\title{
A EPISTEMOLOGIA GENÉTICA DE PIAGET E O CONSTRUTIVISMO
}

\author{
PIAGET'S GENETIC EPISTEMOLOGY \\ AND CONSTRUCTIVISM
}

\author{
Luiz Carlos de Abreu ${ }^{1}$ \\ Márcio Alves de Oliveira ${ }^{2}$ \\ Tatiana Dias de Carvalho ${ }^{3}$ \\ Sonia R. Martins ${ }^{2}$ \\ Paulo Rogério Gallo ${ }^{4}$ \\ Alberto Olavo Advíncula Reis ${ }^{5}$
}

Abreu LCA et al. A epistemologia genética de Piaget e o construtivismo. Rev. Bras. Cresc. e Desenv. Hum. 2010; 20(2): 361-366.

\section{Resumo:}

A Epistemologia Genética defende que o indivíduo passa por várias etapas de desenvolvimento ao longo da sua vida. O desenvolvimento é observado pela sobreposição do equilíbrio entre a assimilação e a acomodação, resultando em adaptação. Assim, nesta formulação, o ser humano assimila os dados que obtém do exterior, mas uma vez que já tem uma estrutura mental que não está "vazia”, precisa adaptar esses dados à estrutura mental já existente. O processo de modificação de si próprio é chamado de acomodação. Este esquema revela que nenhum conhecimento chega do exterior sem que sofra alguma alteração pelo indivíduo, sendo que tudo o que se aprende é influenciado por aquilo que já havia sido aprendido. A assimilação ocorre quando a informação é incorporada às estruturas já préexistentes nessa dinâmica estrutura cognitiva, enquanto que a adaptação ocorre quando o organismo se modifica de alguma maneira de modo a incorporar dinamicamente a nova informação. Por fim, de um pensamento moderno que, buscando a síntese inusitada entre o biológico e o lógico-matemático, parece encontrar seus limites na desconstrução ainda mais inusitada a que tende sistematicamente todo o pensamento na atualidade: a de si mesmo se construindo de modo essencialmente esclarecido.

Palavras-chave: assimilação; estrutura cognitiva; construtivismo; Piaget.

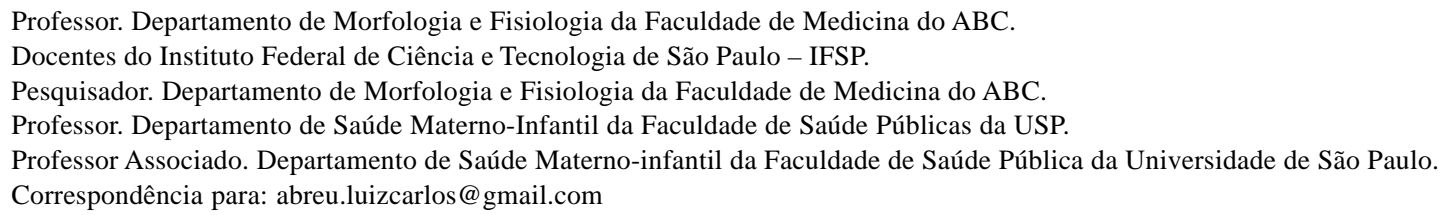




\begin{abstract}
:
The Genetic Epistemology argues that the individual goes through various stages of development throughout his life. The development is seen by the overlap of the balance between assimilation and accommodation, resulting in adaptation. Thus, in this formulation humans assimilate the data they obtain from the outside, but once they already have a mental structure that is not "empty", they must adapt these data to the existing mental structure. The process of change itself is called accommodation. This scheme reveals that no knowledge comes from outside without suffering any change by the individual, and everything that is learned is influenced by what was learned. Assimilation occurs when information is incorporated into pre-existing structures in this dynamic cognitive structure, while the conversion occurs when the organism is changed in some way to incorporate the new information dynamically. Finally, a modern thought that seeking the unusual synthesis between the biological and logical-mathematical seems to find its limits in the deconstruction even more unusual that tends systematically all thought at present: the self developing in a essentially clarified way.
\end{abstract}

Key words: assimilation; cognitive structure; constructivism. Piaget.

\section{INTRODUÇÃO}

O trabalho do epistemólogo suíço Jean Piaget é, sem dúvida alguma, uma das principais contribuições ao entendimento de como o ser humano se desenvolve ${ }^{1}$. A Epistemologia Genética proposta é essencialmente baseada na inteligência e na construção do conhecimento e visa responder à questão não só de como os indivíduos, sozinhos ou em conjunto, constroem conhecimentos, mas também por quais processos e por que etapas eles conseguem fazer isso ${ }^{1,2}$.

A tese fundamental do pensamento piagetiano é a de que somente uma visão desenvolvimentista e articulada do conhecimento - quer dizer não calcada em estruturas pré-formadas, sejam racionalistas, focadas na anterioridade do sujeito, sejam empiristas, focadas na do objeto - pode prover uma resposta a problemas que, tradicionalmente, são evitados pela filosofia de caráter meramente especulativo ${ }^{1-5}$.

O nome Epistemologia Genética, dado por Piaget a sua obra, denota a sua principal preocupação. A Epistemologia é definida como uma reflexão sobre os princípios fundamentais das Ciências: Episteme (Ciência, no sentido mais amplo, para os gregos, e, sobretudo, mas não apenas, fundamentos do conhecimento científico, para nós modernos) + logos (tratado, estudo), destacando, o autor, sua preocupação metodológica a respeito da forma como o conhecimento surge no ser humano, inclusive das raízes mesmas do conhecimento mais elementar, as quais não se absolutizam em um conhecimento primeiro, como, aliás, adverte o próprio Piaget logo na introdução: a grande lição contida no estudo da gênese ou das gêneses é, pelo contrário, mostrar que não existem jamais conhecimentos absolutos ${ }^{1,2}$.

E nesse sentido, ele destaca que a Epistemologia Genética objetiva explicar a continuidade entre processos biológicos e cognitivos, sem tentar reduzir os últimos aos primeiros, o que justifica, e ao mesmo tempo delimita, a especificidade de sua pesquisa epistemológica: o termo genético.

Ainda, destaca que a inteligência é a solução de um problema novo para o indivíduo, sendo uma coordenação dos meios para atingir certo fim, o qual não é acessível de 
maneira imediata; daí o método genético, essencialmente retrospectivo. Já o pensamento é a inteligência interiorizada e se apoiando não mais sobre a ação direta, mas sobre um simbolismo, sobre a evocação simbólica pela linguagem, pelas imagens mentais.

Mas como diz Piaget, ainda anterior ao objeto constituído simbolicamente enquanto tal por um, apenas por então, efetivo sujeito do conhecimento, existe enquanto ação direta, retrospectivamente falando, a zona de contato entre o corpo próprio e as coisas [onde] eles [sujeitos determinados apenas enquanto determinam simultaneamente seu objeto] se empenharão, então, sempre mais adiante nas duas direções complementares do exterior e do interior, e é desta dupla construção progressiva que depende a elaboração solidária do sujeito e dos objetos ${ }^{1,2}$.

Nesse sentido, ele sugere que há evolução natural-cognitiva da aquisição de conhecimentos. Assim, há quatro estágios nos quais os sujeitos são quiescentes para evoluírem, de um estado de total desconhecimento do mundo que o cerca até o desenvolvimento da capacidade de conhecer o que ultrapassa os limites do que está a sua volta ${ }^{1,2}$.

Estágio 1: do nascimento até aproximadamente dois anos de idade, a criança se encontra no estágio sensóriomotor, atingindo um nível de equilíbrio biológico e cognitivo que permite constituir uma estrutura linguística, isto é propriamente conceitual; e isso por volta dos 12 - 18 meses.

Estágio 2: terminado este período, ela adentra no estágio pré-operatório, calcado na constituição ainda incipiente de uma estrutura operatória, e permanece nele até completar mais ou menos 7 - 8 anos, sendo que o equilíbrio próprio é atingido aqui quando a criança está com a idade de 4 - 5 anos.

Estágio 3: operatório concreto. Com início no final do segundo estágio e calcado na capacidade de coordenar ações bem ordenadas em “sistemas de conjunto ou 'estruturas', sus- cetíveis de se fecharem" enquanto tais, ele tem duração, em média, até os 11 - 12 anos. E quanto, especificamente, ao nível de equilíbrio próprio, este acontece aqui por volta dos 9 - 10 anos.

Estágio 4: operatório formal, que se inicia ao final do terceiro e no qual o ser humano permanece por toda a vida adulta, atingindo um estado de equilíbrio próprio por volta dos 14 - 15 anos de idade.

Independentemente do estágio em que os seres humanos se encontram, a aquisição de conhecimentos segundo Piaget acontece por meio da relação sujeito/objeto. Esta relação é dialética e se dá por processos de assimilação, acomodação e equilibração, num desenvolvimento sintético mútuo e progressivo. O dinamismo da equilibração acontece por meio de sucessivas situações de equilíbrio - desequilíbrio - reequilíbrio que visam, por assim dizer, "dominar" o objeto do conhecimento que vai se constituindo nesse processo ${ }^{1-9}$.

A necessidade de conhecimento do objeto pelo sujeito leva-o a executar desde simples ações até operações sobre o objeto. Por um lado, os estágios foram estabelecidos evolutivamente, a partir do que inicialmente faltava enquanto pura necessidade ainda não identificada com um objeto específico enquanto tal, até que se chegasse à capacidade de realizar operações formais pelas quais se abstrai de um objeto visto subjetivamente como puramente em si, e isso após a constituição para si de objetos propriamente concretos.

Mas, por outro lado, para além de um puro fluxo contínuo abstratamente determinante dos estágios em seu abstrato para si, as próprias operações perpassariam três grandes etapas estruturantes que as levariam a se libertar da duração objetivamente do contexto psicológico das ações do sujeito, com o que estas comportam de dimensão causal, para finalmente atingirem esse caráter extemporâneo, essencialmente estrutural e pensado apenas através da reconstituição de 
sua gênese temporal, que é próprio das ligações lógico-matemáticas depuradas ${ }^{10-12}$.

A primeira dessas três etapas perpassadas pelas operações é o da função semiótica, ou seja, a interiorização em imagens e a aquisição da linguagem permitem "a condensação das ações sucessivas em representações simultâneas”, estruturando-se aí um quadro operativo conceitual ainda incipiente a partir de um esquematismo pré-lógico já constituído por uma percepção espaço-temporal de caráter sensóriomotor; nos termos, portanto, do segundo estágio natural-cognitivo de aquisição dos conhecimentos, o que se dá, precisamente, por volta dos 18 meses - 2 anos ${ }^{1,2}$.

A segunda das etapas coincide com o início do terceiro estágio, das operações concretas, coordenando as antecipações e as retroações que chegam a uma reversibilidade suscetível de refazer o curso do tempo e de assegurar a conservação dos pontos de partida, porém de modo ainda demasiado preso aos objetos percebidos concretamente como em si mesmos.

Apenas numa terceira etapa, o sujeito do conhecimento supera o real e insere-se no possível, ou seja, consegue de modo paradoxal extemporaneamente "relacionar diretamente o possível ao necessário sem a mediação indispensável do concreto".

Dentre as teorias do conhecimento já elaboradas, é possível que a Epistemologia Genética seja uma das mais completas, e justamente pela negligência de um estudo mais sistemático das origens naturais-cognitivas do conhecimento por parte de uma epistemologia mais tradicional, se seguirmos o que diz o próprio Piaget na introdução desta sua obra, ela seria completa não só porque abrange a aquisição de conhecimentos pelo homem, desde o nascimento até a idade adulta, mas também porque ela procuraria responder, com certo nível de detalhamento prático e teórico, quais são os processos naturais-cognitivos dessa aquisição $0^{1,2}$.
Desta maneira, o objetivo da Epistemologia Genética é, em última instância, prover e expor os desvendamentos bem como abarcar as raízes das diversas variedades de conhecimento, e isso desde as suas formas mais elementares até a evolução observada nos níveis seguintes, inclusive no pensamento científico.

A ênfase está, portanto, na construção, ou melhor, na reconstrução dos caminhos pelos quais o indivíduo evoluiu de um estado inicial pré-linguístico até um determinado estado atual, onde é amplamente capaz de um formalismo linguístico.

Logo, é uma teoria estruturalista na qual o conhecimento é um processo se estruturando e não um estado já cristalizado; e nesse sentido é uma teoria realista, propriamente em oposição seja ao empirismo seja a um racionalismo idealista, a priori de tipo kantiano, pois o desenvolvimento da criança é, sobretudo, um processo histórico; segundo duas direções: a psicossocial e a de um espontaneismo biológico, o qual remete a certo realismo de tipo naturalista ${ }^{1,2}$.

Assim, Piaget busca diferenciar de uma mera associação positivista a estruturas linguísticas, em última instância pré-determinadas e de fundo essencialmente empirista, algo como uma assimilação dos conteúdos por esquemas essencialmente objetivos, que vão se estruturando extemporaneamente conforme o desenvolvimento natural-cognitivo do próprio sujeito do conhecimento; tendência mútua de continuidade e ruptura que vai retrospectivamente além das operações causais sobre objetos para operar abstratamente sobre o próprio processo operativo, reconhecido lógico-matematicamente como sendo o de assimilação dos conteúdos; e isso conforme três tipos de pro$\operatorname{cessos}^{1-12}$ :

1. Assimilação generalizadora: ocorre quando esquemas estruturantes se modificam de modo a assimilar novos e problemáticos objetos da realidade em função de uma totali- 
dade esquematicamente ainda mais generalizante, tendendo mesmo à formalização.

2. Assimilação reconhecedora (discriminante): é a capacidade desses esquemas de buscarem os objetos seletivamente a partir de uma ou mais características dos objetos experienciados, estruturados estes apenas a partir da ativa construção lógico-matemática de um efetivo sujeito do conhecimento.

3. Assimilação recíproca: neste caso, dois ou mais esquemas se fundem em uma totalidade generalizante de maior hierarquia, pois para Piaget só nos aproximamos da estrutura das coisas por aproximações sucessivas, nunca definitivas.

Quanto ao alcance epistemológico e mesmo pedagógico do construtivismo piagetiano, bastante influente no processo educativo das últimas décadas, poder-se-ia fazer apenas crítica genérica de seu processo de solidificação conceitual e prática, destacandose a incapacidade do sistema educacional, e não só dele, em formar professores com condições de aplicar essa teoria essencialmente desenvolvimentista na situação real de uma crise dos paradigmas modernizantes calcados num sentido efetivo do progresso humano.

Contexto esse que reflete, portanto, mais do que uma mera deficiência do sistema escolar, numa crise social que alcança o próprio sistema de conhecimentos historicamente estabelecidos com certa naturalidade, seja físico-mecânico ou mesmo lógico-matemático de fundo biológico, ainda que intersubjetivamente constituído.

E nesse sentido, para além das dificuldades meramente conjunturais de estruturação cognitiva, por mais absolutas que pareçam e paradoxalmente o são, é necessário considerar um certo caráter patológico da própria estruturação social ${ }^{1,2}$. O que parece alcançar mesmo o próprio nível de uma suposta naturalidade biológica e que direciona as expectativas sociais e individuais de estruturação formal progressiva da realidade no sentido de diluir aí maiores contradições, através da ênfase numa tendência naturalista-cognitiva.

De qualquer forma, destaca-se que os dois conceitos fundamentais da teoria piagetiana, e de um alcance epistemológico fundamental, são os conceitos de assimilação e adaptação, e que por eles se busca, com acertos e desacertos típicos da atual fase da modernidade, um processo dinâmico que dê conta justamente desse limite tênue entre o natural e o social numa realidade moderna complexa como a nossa.

A assimilação ocorre quando a informação é incorporada (sob forma modificada ou não) às estruturas já pré-existentes nessa dinâmica estrutura cognitiva, enquanto que a adaptação ocorre quando o organismo se modifica de alguma maneira de modo a incorporar dinamicamente a nova informação ${ }^{1,2}$.

E assim os estágios piagetianos se constituem em diferentes esquemas de interação entre o sujeito e o mundo externo, com mútuas determinações destes e daqueles conforme uma complexa estrutura natural-cognitiva que se constitui na medida em que a inteligência rompa tanto com a naturalidade objetiva em si quanto com a subjetiva para si, reflexo, de um pensamento moderno que, buscando a síntese inusitada entre o biológico e o lógico-matemático, parece encontrar seus limites na desconstrução ainda mais inusitada a que tende sistematicamente todo pensamento na atualidade: a de si mesmo se construindo de modo essencialmente esclarecido.

Assim, é de se concordar que: são os comportamentos, não as pessoas, que estão em estágios; a idade é um indicador e não um critério de desenvolvimento; é a necessidade lógica, não a verdade, a questão central; a construção do conhecimento não é uma tarefa individual, mas social; e que as estruturas de conjunto são critérios formais mais do que entidades funcionais ${ }^{12,13}$. Ainda, que não há apenas um, mas múltiplos percursos desenvolvimentistas, e que o que os sujeitos fazem ao raciocinar não é seguir regras lógicas, mas agir e operar em conteúdo e significado, no desempenho da compreensão epistêmica. 


\section{REFERÊNCIAS:}

1. Rosa, Paulo Ricardo da Silva. Instrumentação para o Ensino de Ciências. Disponível em: http:/

www.dfi.ccet.ufms.br/prrosa/Pedagogia/ index.htm. Acesso em: 07/07/2010.

2. Pádua, Gelson Luiz Daldegan. A epistemologia genética de Jean Piaget. Revista FACEVV, vol. 1., 2009. Número 2. p. 22-35.

3. Fraysse, J. C. (1994). Combined effects of friendship and stage of cognitive development on interactive dynamics. The Journal of Genetic Psychology, 155 (2), 161-177.

4. Guimarães, KP e Breneli, RP. Pedagogical intervention through Ring Toss Game and the construction of the notion of multiplication: a Piagetian study. Disponível em: Rev. eletr. psicologia e epistemologia. Volume 2. Número 3 (Jan-Jul), 2009. Acesso em 2010-14-07.

5. Downs, R. M. \& Liben, L. S. (1993). Mediating the environment: Communicating, appropriating and developing graphic representations of place. Em R. H. Wozniak \& K. W. Fischer (Orgs.), Development in Context. Acting and thinking in specific environments (pp. 155181). Hillsdale, NJ: Lawrence Erlbaum.

6. Moro, M. L. F. (1991). Crianças com crianças, aprendendo: Interação social e construção cognitiva. Cadernos de Pesquisa, 79, 31-43.
7. Moro, Maria Lucia Faria. A epistemologia genética e a interação social de crianças. Psicol. Reflex. Crit. [online]. 2000, vol.13, n.2 [cited 2010-07-14], pp. 295-310 . Available from: <http://www.scielo.br/ scielo.php?script=sci_arttext\&pid=S010279722000000200009\&lng $=$ en\&nrm=iso $>$. ISSN 0102-7972. doi: 10.1590/S010279722000000200009.

8. Piaget, J. (1962). Commentaires sur les remarques critiques de Vygotsky. Em B. Schnewly \& J. P. Bronckart (Orgs.), Vygotsky aujourd'hui (pp.120-137). Neuchâtel/Paris: Delachaux et Niestlé.

9. Perret-Clermont, A. - N. (1987). Rapport d'activité du séminaire de psychologie, Université de Neuchâtel. Cahiers de Psychologie, 26, 43-56.

10. Piaget, J. (1973). As operações lógicas e a vida social. Em J. Piaget (Org.), Estudos sociológicos (pp.164-193). Rio: Forense (Original publicado em 1945).

11. Fraysse, J. C. \& Desprels-Fraysse, A. (1987). Apprentissage et développement: Une approche génétique. Enfance, 40(3), 231-244.

12. Lourenço, Orlando e Machado, Armando. In Defense of Piaget's Theory: A Reply to 10 Common Criticisms. Psychological Review, 1996. Vol. 103, No. I, 143-164.

13. Lourenço, Orlando. Além de Piaget? Sim, mas primeiro além da sua interpretação padrão! Análise Psicológica (1998), 4 (XVI): 521-552.

Recebido em 02 de julho de 2010 Modificado em 15 de julho de 2010 Aceito em 30 de julho de 2010 